To cite this Article: K. Aalto-Korte, R. Kurimo, J. Laitinen, M. Pesonen, E.P. Takala, M.A. Poutanen (2016) CONTINUING VOCATIONAL TRAINING FOR TEACHERS IN BEAUTY AND HAIR CARE - TEACHERS ACT AS ACTIVE DEVELOPERS OF THEIR WORK AND ENGAGE IN TRANSFERRING GOOD PRACTICES TO THEIR STUDENTS, ICERI2016 Proceedings, pp. 2386-2394.

DOI: $10.21125 /$ iceri.2016.0152

URL: https://library.iated.org/view/AALTOKORTE2016CON 


\title{
CONTINUING VOCATIONAL TRAINING FOR TEACHERS IN BEAUTY AND HAIR CARE - TEACHERS ACT AS ACTIVE DEVELOPERS OF THEIR WORK AND ENGAGE IN TRANSFERRING GOOD PRACTICES TO THEIR STUDENTS
}

\author{
K. Aalto-Korte ${ }^{1}$, R. Kurimo ${ }^{2}$, J. Laitinen ${ }^{1}$, M. Pesonen ${ }^{1}$, E.P. Takala ${ }^{1}$, \\ M.A. Poutanen ${ }^{2}$ \\ ${ }^{1}$ Finnish Institute of Occupational Health (FINLAND) \\ ${ }^{2}$ Laurea University of Applied Sciences (FINLAND)
}

\begin{abstract}
This paper describes the experiences of students and organizers of the Hair and beauty care, the prevention of health hazards (HIKAT) project which offered nationwide continuing vocational training (CVT) for teachers in beauty and hair care to be further disseminated in vocational secondary education.

The development of occupational skin diseases is one of the most important health risks related to the exposure to chemical and physical risks in hairdressing. The prevention of occupational skin diseases is the overall aim in European countries.
\end{abstract}

The aim of the HIKAT project was to increase hair and beauty care teachers' skills to guide students future professionals - to work safely. Another aim was to increase teachers' knowledge and help them develop good practices in their own work.

The studies in the project were based on the Learning by Developing (LbD) model as part of students' competence development. Laurea University of Applied Sciences created the LbD model based on authenticity, partnership, experiential learning, creativity and research. Learning is related to development projects that are genuinely rooted in working life.

The project was carried out in two phases mainly as blended learning and on-line. The studies were based on a theoretical approach - using literature, written assignments, lectures and group work. In addition, the participating students practically developed the theoretical background, first testing the pedagogical methods and then adopting the best practices into their own work. Assignments were designed so that they were transferred directly to the participating teachers' own classroom. Materials and tools were integrated into the vocational schools' practical teaching, so that the pupils created practical exercises relevant to their future occupation. Participating teachers also compiled portfolios, which were presented at the end of the studies.

The studies were performed in four modules. The students were allocated to four groups that reflected on and shared on-line experiences of the assignments. The topics of the modules were 1) Cosmetic ingredients, cosmetics legislation, microbiology, and allergenic ingredients 2) Occupational skin and respiratory diseases and allergies 3) Ergonomics and safety of the workplace 4) Promotion of workability and health through healthy lifestyle. The students' experiences were collected using feedback questionnaires after each module and at the end of the project.

25 completed the studies of 20 credits. The opportunity to act as developers in the work environment supported the teachers' professional competence development. By working in a blended learning environment and co-operating with other professional groups in the haircare and beauty sector, the teachers created new operation models and demonstrated them to their peer students and work community. In the feedback and discussions several teachers reported that the developments in the project were disseminated and adopted widely as new practices in their vocational schools. Portfolios and a project summary presented the strong development of occupational and cognitive competence, especially in the field of work safety and wellbeing. One of the main results from the educational institutional point of view was the successful combination of three different levels of education: vocational school, university and research institute. This led to the synthesis of expertise which was directly disseminated to vocational education students.

Keywords: Vocational education, LbD, good practices, adult education, SafeHair. 


\section{INTRODUCTION}

The lengthening of career duration $s$ a big challenge to the Finnish society. Hairdressers often change their work field even though they find the work as a hairdresser appealing. Hand dermatitis and musculoskeletal diseases are the most common reasons. Career breaks caused by the health problems and retraining into new professions shorten the duration of working careers. In the hairdresser's work there is a high risk of hand dermatitis; even $70 \%$ of the hairdressers will develop skin symptoms at some stage. The skin problems often begin already during the studentship. To reduce skin problems prevention is the most efficient way and it would be good to learn the principles of skin protection already in connection with the education.

Hairdressers suffer from pains in the upper limbs, shoulders and back. Research papers indicate that when attention is paid to the ergonomics in the planning of work premises, in the acquisition of the pieces of furniture and tools, in the choice of approaches and in the arrangement of work problems caused by the work are reduced.

There is less research information about beauty therapists' work-related skin problems but this profession is also associated with a high risk for occupational skin disease. The use of acrylatecontaining structure nails has increased the incidence of contact allergies and occupational skin and respiratory diseases.

The health aspects have been brought up in the curriculum of hairdressers and beauty therapists. The studies of the ways to promote and maintain work ability through healthy lifestyles are also to be included in the curricula of vocational education.

The need for the knowledge about the prevention of hairdresser's dermatitis is well-known at the EU level. Safehair2010 is a website, where material about hairdressers' skin protection is collected [1]. It was developed in research projects that were funded by the EU. The European framework agreement on the protection of the occupational health and safety in the hairdressing sector was signed in April 2012 by the hair industry employers' (Coiffure EU) in and workers' organizations (UNI Europa Hair and Beauty). This agreement covers not only protection of the skin and respiratory tract, but also the prevention of musculoskeletal problems, maternity protection, mental health and well-being.

The aim of the HIKAT was to offer nationwide continuing vocational training (CVT) for teachers in beauty and hair care to be further disseminated in vocational education. Study materials and assignments related to the health and safety at work and work performance became an integral part of the participants own practical teaching. Participants also developed and piloted teaching and learning methods during the training.

The long-term aim of the project was to increase the teachers and their students' knowledge of wellbeing at work and work ability. The project presented the instruments, with the help of which hair and beauty care experts can take care of their work ability in the world of work. As entrepreneurs, they have to be able to take care of the potential of their employees to work. The knowledge about raw materials helps them to choose suitable products for consumers suffering from allergies and skin symptoms.

\section{DESIGNING OF THE CONTINUING VOCATIONAL TRAINING, HIKAT}

In 2013 Laurea University of Applied Sciences and the Finnish Institute of Occupational Health (FIOH) decided to launch a joint project. Funding for the project was applied from The Finnish National Board of Education. Already at the early stage of the project design a number of vocational colleges were contacted and asked about their willingness to take part in the designing of the project. In April 2014, the first meeting was held attended by representatives from Laurea University of Applied Sciences, Finnish Institute of Occupational Health and from six vocational schools. The draft of curriculum was established in the second meeting in September 2014.

The training was designed to be divided into four different modules, five ECTS credit points each. Two representatives from vocational colleges were elected for each module, which ensured that the assignments in the project could be implemented in colleges. The experts from The Finnish Institute of Occupational Health visited the vocational colleges during the design period.

In September 2014 an e-poll was carried out where more than 50 Finnish hair and beauty care vocational colleges were asked about their willingness to take part in the HIKAT project. In less than a month for a total of 36 replies were received from 21 schools. According to the answers, vocational 
schools were willing to send a total of more than 80 teachers to take part in the continuing vocational training nationwide. The funding application was sent in January 2015.

After positive funding decision vocational colleges were informed about the project and binding enrolments were asked. 14 beauty therapists and 21 hairdresser teachers enrolled the project.

\section{THE STRUCTURE OF THE HIKAT PROJECT}

The HIKAT project began in October 2015 and training ended in May 2016. Reporting and statistics analysis will continue until the end of 2016. The extent of the training was 20 ECTS and it was divided into four 5 ECTS credit point modules.

1 The raw material of knowledge

2 Skin diseases, allergies and respiratory diseases, occupational health and safety

3 Ergonomics, and the structure of the workplace

4 Work ability, welfare of the work community, well-being and healthy lifestyles

The content of the first module was on Laurea UAS's responsibility. The Finnish Institute of Occupational Health took care of the other three modules. The training was carried out mainly in the Laurea Optima platform.

The need for specialized knowledge about cosmetic raw materials was clear already at the beginning of the project design.

Education consisted of three contact days on Laurea Tikkurila Campus. The contact days were not mandatory, but recommended. The rest of the studies were on-line. The educational criteria of the financing were that the target group was teachers from secondary schools and vocational colleges.

The training was launched on the first contact day at the beginning of October 2015 when the training as a whole was presented in more detail. In the first contact day, the trainees were introduced to the network environment as well as electronic study materials.

The other contact days were at the beginning of February and at the end of May. The modules were started during the contact days with content-related expert lectures and group work. In the last contact day the students presented their learning diaries and gave feedback of the whole training.

\subsection{Learning objectives of the modules}

In module one the learning objectives were stated as follows: "The teacher can identify the most centric chemical compounds of cosmetic products of her field and understands their action. The teacher can take into consideration product selections and the allergies caused by the ingredients. The participant identifies the legislation concerning these compounds and understands the significance of the updating of the information. She integrates into her own teaching the matters above. The teacher can use cosmetic products in a correct way and can guide students to their safe and lawful use."

In module two the learning objectives were stated as follows: "The teacher can identify the main causes of the skin and the respiratory health risks and knows what kind of health problems they can cause and their consequences. The teacher knows the means to the control of health risks. The participant is motivated to integrate the prevention of health risks in their own work, and to convey information about the causes of risks and means of protection for the students, colleagues and in the workplace."

In module three the learning objectives were stated as follows: "The teacher can identify and apply the items related to work safety and ergonomics in the training of vocational students."

In module four the learning objectives were stated as follows: "The teacher can identify the most central sectors that maintain the workability and their significance in her own work. The teacher can transmit information in her own teaching."

\subsection{Methods used in the studies}

In module one the participating teachers worked with their students as well as with their colleagues. The teachers tested their colleagues about their knowledge of legislation and they practised cosmetic 
legislation details with their students. The teachers were allowed to conduct the assignments in a creative manner to suit their own work. Participating teachers made a developing assignment in order to observe targets for microbial contamination in their work environments. They made a list about potent microbial risk targets/places and made propositions to avoid the risks.

Module two (Skin diseases, allergies and respiratory diseases, occupational health and safety) included several practical tasks and exercises which the participating teachers conducted in the class rooms together with their own students and colleagues. In one of them, participants reviewed their own working environment, i.e. the classrooms, with their students by utilizing a ready-made check-list on e.g. occupational safety, workplace contamination assessment, availability and material of safety gloves and their usage as well as various other details on health-promoting work procedures and awareness of the importance of protecting the skin and respiratory organs. Teacher and the students then edited the check-list and made a version adjusted to the needs of their own working environment.

Participating teachers evaluated their students' knowledge and attitudes on allergens, irritants and skin protection in hairdressing and beauty therapy This was done by using the network teaching tool, Kahoot!, where two series of questionnaires (a Quiz and a Survey) were provided for the participating teachers. Removing protective gloves without contaminating the skin of the hands is a challenge, and this was addressed in one of the tasks. The teachers first documented the importance of using the correct glove removal method by a practical demonstration which involved staining the students' gloves with harmless coloured substance and an attempt by the students to remove the soiled gloves the best they could, then taught them the correct glove removal method with the help of a video and a picture series.

Two posters, which highlighted the skin protective work practices and appropriate skin care routines in hairdressing and beautician's work were provided as possible educational tools. The teachers placed the posters in their classroom and evaluated their usefulness as an educational material together with their students and colleagues, and also made changes and additions on the posters to adjust them to their workplace and educational needs. In module two, the hairdressing and beauty care teachers were also encouraged to develop work procedures which reduce the skin exposure to harmful substances at work, and to better promote the safe work habits and practical skin and respiratory protection in their schools and teaching. This was done by means of virtual group discussions among the participants of HIKAT.

Methods used in module three are described in detail below, in chapter 3.3.

In module four the participants participated first in workshop using Hitting home tool that aimed to increase their own knowledge on the determinants and demands of work ability in their own occupation [2]. Hitting home tool is a joint development model for work ability promotion activities for small and medium-sized companies. The tool offers a community-oriented way to find the development areas related to well-being at work and work ability. After that teachers were asked to use Hitting home tool with their own students and to reflect and report their experiences from that. Secondly, they were asked to evaluate a list of materials (books, leaflets etc.) related to the promotion of workability by healthy lifestyles. The third task was to make a plan of a teaching session named promotion of work ability by the topic or theme that raised from the Hitting home workshop, thus, choosing this theme tailored the teaching according to the needs of the students. The teaching plan included the aims of the session, contents, teaching methods and evaluation of learning.

\subsection{Module 3, Ergonomics and the structure of the workplace}

Module three, Ergonomics and the structure of the workplace, is presented here in detail showing the learning objectives, used methods, results and discussion. All the other modules are discussed in this paper in general.

\subsubsection{Learning objectives}

In this module the learning objective was stated as follows: "The teacher can identify and apply the items related to work safety and ergonomics in the training of vocational students." In details this means that the teachers should be able to 1) Know the teachers' responsibilities to teach issues related to safety and ergonomics to vocational students, and 2) Evaluate and develop her/his teaching; 3) Systematically observe the work for ergonomic analysis and; 4) Develop ergonomics together with the vocational students. For the aims 3 and 4 the teachers developed a tool (check-list) to evaluate the work. 
The ultimate aim was that the vocational students will adopt know-how on safety and ergonomics in their future occupation by training these skills in the vocational school.

\subsubsection{Methods}

In the beginning of this module the first meeting day included three lectures on the general principles of 1) occupational safety, 2) ergonomics, and 3) development of work. It was emphasized that the focus of ergonomics is on the work - human interaction and the whole working system shall be evaluated (not only e.g. individual working postures or hand-tools). To rank the importance of risks and problems the general risk assessment scheme was taught (the importance of risk is a combination of the probability and the severity of the consequences of the occurrence). For the development of work the plan-do-check-act (PDCA) method was recommended.

For this module the instructor Esa-Pekka Takala scanned systematically internet to find suitable public reference material on occupational safety and ergonomics in hairdressing and beauty occupations. The final set included publications in Finnish on the sites of the Finnish Institute of Occupational Health, The Centre for Occupational Safety, and The Finnish National Board of Education, and in English on the sites of the Occupational Safety and Health Administrations (OSHA) in Europe and USA.

The teachers were instructed to do the following tasks in order to construct their know-how:

1 'Read the sections 'Skills for working life' in the official document on the curriculum for vocational schools. Describe the way you teach safety and ergonomics to your students. Then read the national guidelines on safety and ergonomics in vocational colleges for hairdressing and beauty care and append your reflections about your teaching."

2 "Read the given material about occupational hazards. On the list of general hazards select the items that are relevant in the future occupation of your students and describe examples of each hazardous situation. Think, what your students as future employees or employers should know in order to avoid and manage the hazards. How should you teach these skills?"

3 "To append your list read the given examples on occupational safety check-lists for the hairdressers and beauty workers and construct your own checklist. Compare the lists of your peer students and make a common check-list in consensus with your group."

4 "List the tasks of the hair and beauty occupations. With your check-list go through each task and evaluate the potential risks (probability and consequences). Select the tasks of highest risks and think potential solutions to manage them. How should you teach these skills?"

5 "Test your construct (check-list) in the classroom interactively with the vocational students by letting them to perform the evaluation of their work. Describe your experiences."

6 "Read your products in tasks 1 and 2. How would you write your response now? What have you learned in this module?"

The students were instructed to do these tasks first independently and then to append their products in the group discussion on the chat-area.

\subsubsection{Results}

All 25 students, who had finished this module, described in their responses that the tasks had been valuable for their work and helped them to conceptualize occupational safety and ergonomics clearer and deeper than before the training. Some vocational schools already had own check-lists and this process helped them to append these lists of the schools. Letting the vocational students perform the evaluation had also been successful. Many teachers reported that they will go on with this exercise in their future teaching. Many had also demonstrated the exercises to their peers and disseminated the experiences to common discussions in their schools to develop the fulfilling of the obligation stated in the official curriculum.

In the chat the amount of discussion varied; some groups had very active discussion while in some groups only few students were active. The tasks were also stated to be time consuming and demanded plenty of work beside the working hours at school. 


\subsubsection{Discussion}

The training of occupational safety and ergonomics by letting the teachers construct check-lists to be used by the future employees seems to be a promising way of learning by doing in vocational schools.

The variation of participation in the chat discussions emphasizes the importance to thoroughly activate student groups for this kind of co-working.

\section{RESULTS}

25 teachers, $71.4 \%$ from the participants, finished the vocational training acceptably during the school year. Ten teachers abandoned the training. Few announcements about discontinuation came up already in the middle of the training and the rest during the spring term.

The reasons for the discontinuation were, for example, changed situation in teachers own work, such as new responsibilities and changed situations in personal life. New curriculum in secondary schools was mentioned as a reason for discontinuation, when teaching and contents were significantly reformed in comparison with the previous curriculum.

\subsection{Feedback}

Feedback was collected with e-form query after each module. Feedback forms were similar after each module, except after Module 2 additional questions were asked. Feedback questionnaire and results from each module are shown in bar diagrams. The answers were very similar in all modules, therefore the summary of all the answers is presented in this paper.

Questions 1, 4, 5. According to the feedback, Fig.1-Fig.4., the contents of the modules were good and the quality of the training material was considered useful in all modules, all the answers were values 45 on a scale of 1-5.

According to the feedback, learning objectives were appropriate and supported the participating teachers work and development of their knowledge (questions 2 and 6, values 4-5), Fig.1-Fig.4.

Sometimes it was a challenge to integrate the education into teachers own work, teaching. For example, there were difficulties to find an appropriate student group with which to do the assignments (question 7, values 3-4) Fig.1-Fig.4. That was the case especially with modules with smaller assignments. Integration was easier with modules were the assignments were bigger and more collective.

In questions 9 and 10 , feedback about tutoring was asked. Participants were satisfied with the quality and the quantity of tutoring, the values were in between 3.5-4.2. Fig.1-Fig.4. About network environment, Optima, the values in responses were 3.9-4.1, question 11, Fig.1-Fig.4. 
1. Module 1 formed a well set with good contents

2. In the 1 st module the objectives were suitable and supported the development of my work and my know-...

3. The lecture on the legislation was useful

4. The educational material was of high quality

5. Educational material was useful to my own teaching

6. The tasks and materials related to them supported my learning

7. I succeeded in integrating the tasks of the 1st module well into my own teaching

8. The working pace and schedule were suitable

9. I am satisfied with the obtained guidance and supervising

10. I have got guidance and supervising when needed

11. The used network environment was suitable for the education

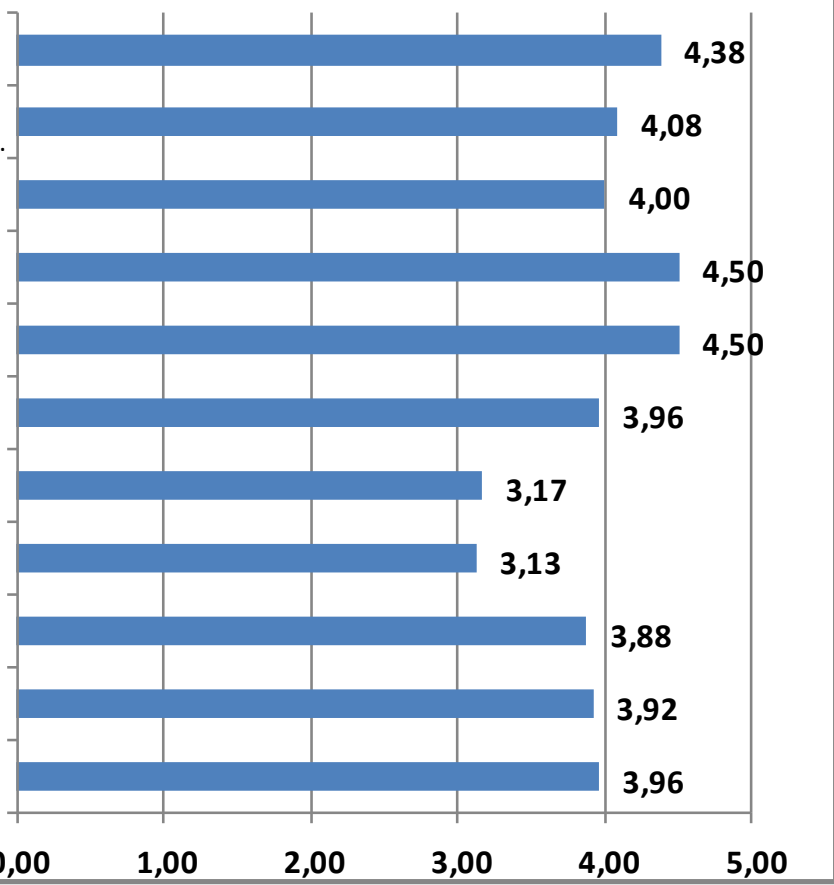

Figure 1. Feedback from Module 1. The values are presented as average. Total number of answerers were 24. On X-axis average values are presented. $1=$ Totally disagree, $2=$ Disagree, $3=$ Do not disagree or agree, $4=$ Agree, $5=$ Totally agree.

1. Module 1 formed a well set with good contents

2 . In the 2 nd module the objectives were suitable and supported the development of my work and my know-..

3. The lecture on the professional rashes of a hair and beauty care was useful

4. The educational material was of high quality

5. Educational material was useful to me to my own teaching

6. The tasks and materials related to them supported my learning $g$

7. I succeeded in integrating the tasks in the 2 nd module well into my own teaching

8. The working pace and schedule were suitable

9. I am satisfied with the obtained guidance and supervising

10. I have got guidance and supervising when needed

11. The used network environment was suitable for the education

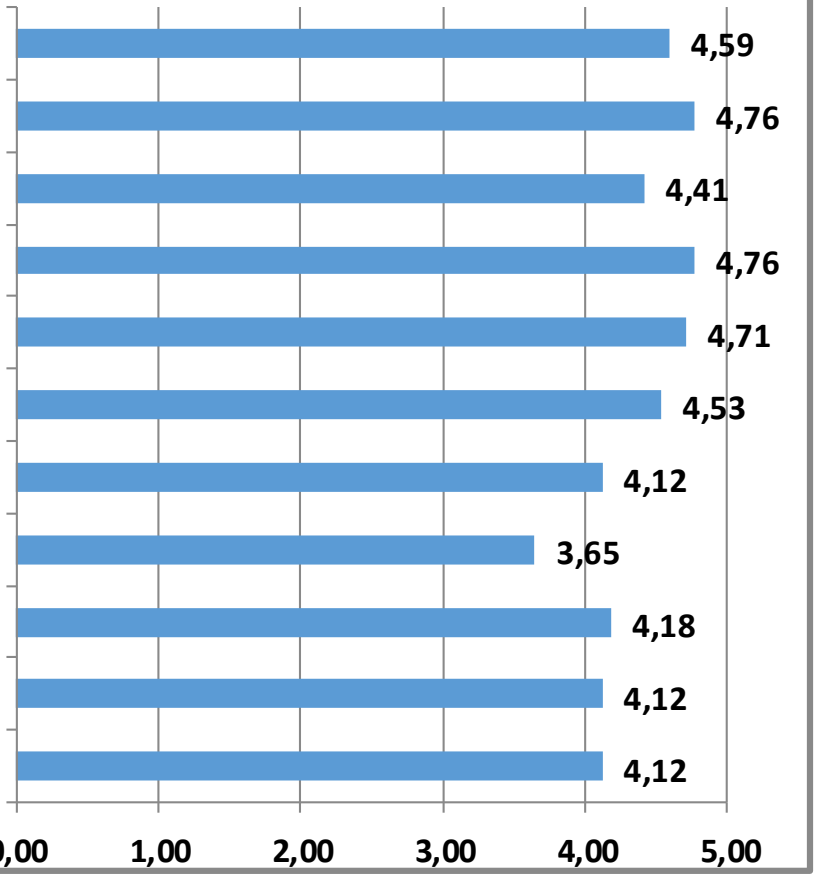

Figure 2. Feedback from Module 2. The values are presented as average. Total number of answerers were 17. On X-axis average values are presented. $1=$ Totally disagree, $2=$ Disagree, $3=$ Do not disagree or agree, $4=$ Agree, $5=$ Totally agree. 
1. Module 1 formed a well set with good contents

2. In the 3 rd module the objectives were suitable and...

3. The start lecture on the ergonomics was useful

4. The educational material was of high quality

5. Educational material was useful to my own teaching

6. The tasks and materials related to them supported...

7. I succeeded in integrating the tasks of the 1 st...

8. The working pace and schedule were suitable

9. I am satisfied with the obtained guidance and...

10. I have got guidance and supervising when needed

11. The used network environment was suitable for the...

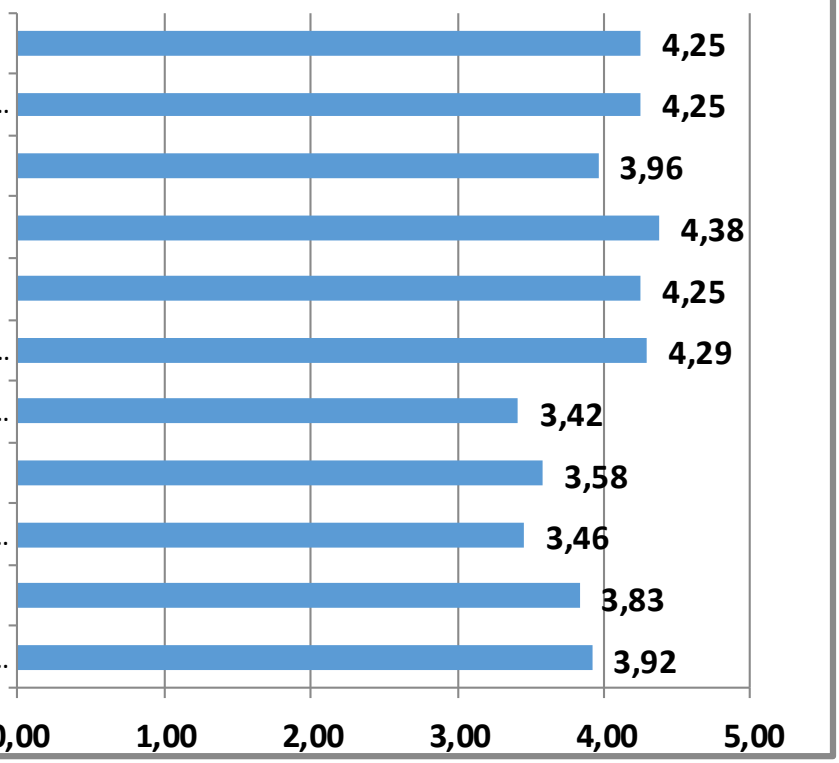

Figure 3. Feedback from Module 3. The values are presented as average. Total number of answerers were 24. On X-axis average values are presented. $1=$ Totally disagree, $2=$ Disagree, $3=$ Do not disagree or agree, $4=$ Agree, $5=$ Totally agree.

1. Module 1 formed a well set with good contents

2. In the 4 th module the objectives were suitable and...

3. The start lecture of the occupational health/the...

4. The educational material was of high quality

5. Educational material was useful to my own teaching

6. The tasks and materials related to them supported...

7. I succeeded in integrating the tasks of the 4 th...

8. The working pace and schedule were suitable

9. I am satisfied with the obtained guidance and...

10. I have got guidance and supervising when needed

11. The used network environment was suitable for...

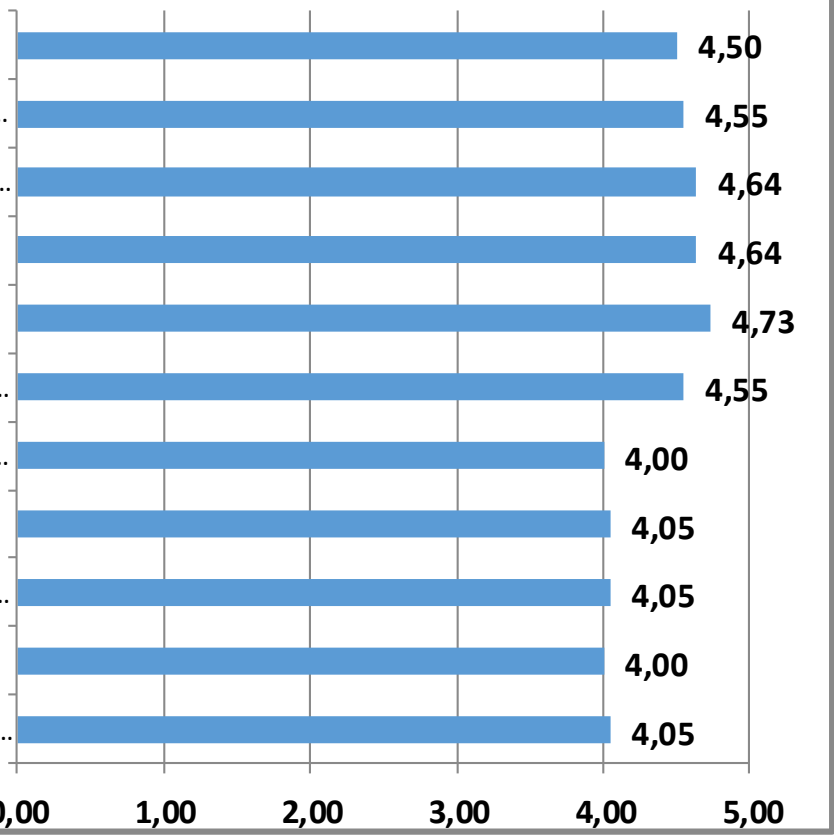

Figure 4. Feedback from Module 4. The values are presented as average. Total number of answerers were 22. On X-axis average values are presented. $1=$ Totally disagree, $2=$ Disagree, $3=$ Do not disagree or agree, $4=$ Agree, $5=$ Totally agree.

According to the verbal feedback, the participants found the platform complex, especially with numerous assignments and their moderation.

Verbal feedback acknowledged many things in this project. In particular, the materials and a number of tasks and assignments in all modules were useful, educational and inspiring. Participants reported that they will use the material and assignments in their own work in the future.

Assignments were designed to be done in cooperation with colleagues, which was not always possible. The new curriculum was launched in secondary schools in 2015 and the amount of time for 
theory based teaching decreased. Teachers reported that sometimes there was not sufficient time to go through the tasks with colleagues. Group work was hindered by teachers' different schedules.

\section{DISCUSSION}

Tight schedule from the funding decision to the beginning of the project hampered the design, implementation and realisation of vocational training. In the future, it would be good to have more time for the financial planning and constructing training materials. This time the time was four months and summer break, two months, shortened the time for design.

Many remarks in the feedback were justified and could be repaired with the better scheduling. Due to short project design time the utilizing of the representatives of pilot schools did not succeed in the best possible way.

The objectives set for every module came true well from the organizer of the education point of view between the ones who completed the studies. On the basis of the feedback, the participants were satisfied with teaching and implementation of teaching. Especially materials in all modules were acknowledged. In modules two and three the checklists were singled out as good practices.

The feedback, as a rule, was good and in the verbal feedback many assignments were experienced useful and were brought out to the participants' own teaching. On scale 1-5 all the response values were over 3 and the majority of the answers were over 4 .

On the basis of the feedback, the next vocational training project should be planned in detail well in advance. This would ensure that the students receive all the information about training, contents and tasks and schedules in a timely manner.

In addition, the tasks performed in practice, and how they serve in teachers own working environment would benefit from a comprehensive tutoring already at the beginning of the project.

More exact becoming acquainted with the changed secondary school curriculum and its practices could produce tasks more suitable for the environment in question. Tighter cooperation with the second degree pilot schools would benefit both organizers and attending schools.

The scheduling and the use of the network environment are clear subjects of development to the following projects.

The scheduling of the education, with two education degrees and with the third expert organization was challenging but the final result was successful. In the education the participants developed their own teaching together with their colleagues when they tested in their own work with their own students the educational material to be used.

\section{ACKNOWLEDGEMENTS}

The Finnish National Board of Education is appreciated for funding the project.

\section{REFERENCES}

[1] SafeHair, http://www.safehair.loungemedia.de/safehair/homepage.html

[2] Hitting Home? Joint development model, cited 28.9.2016.

http://www.ttl.fi/en/research/research_projects/alert_behind_the_wheel/Documents/HITTING\%2 OHOME.pdf 